\title{
Diabetic Autonomic Neuropathy
}

\author{
The Diagnostic Value of Heart Rate Monitoring
}

J. D. Mackay, M. McB. Page, J. Cambridge, and P. J. Watkins

Diabetic Department, King's College Hospital, London, England

Summary. The use of heart rate monitoring in the diagnosis of diabetic autonomic neuropathy, and its value in observing the natural history of this disorder, has been assessed. Two tests were used: measurement of heart rate variation during deep breathing and of heart rate change on standing up. Two hundred and eighty seven diabetics aged between 20 and 49 years were studied, and 21 of them were observed repeatedly over 3 to 5 years. Heart rate variation (HRV) on deep breathing proved to be the more sensitive diagnostic index of autonomic neuropathy and was abnormal or borderline in 62 of 64 patients with established autonomic symptoms. Autonomic abnormalities were also detected in some diabetics without autonomic symptoms especially in those with peripheral neuropathy, $30 \%$ of whom had abnormal HRV on deep breathing. Abnormal tests appeared to represent permanent autonomic damage and may be present for years without the development of autonomic symptoms, occasionally $(7 \%)$ preceding any other manifestation of diabetic neuropathy. Serial observations of HRV on deep breathing over 3 to 5 years showed little change, although overall there was a small deterioration of autonomic function, with a decrease of HRV score of 1.0 per year. The tests used are simple, and provide quantitative bedside measurements of autonomic function. When heart rate variation is normal, autonomic neuropathy is virtually excluded.

Key words: Diabetes, autonomic neuropathy, peripheral neuropathy, heart rate.

Autonomic neuropathy can be the cause of a crippling illness although in some patients it results in no symptoms at all. In 1945 Rundles [1] presented the first comprehensive review of its diverse symptoms, later amplified by others $[2,3]$. Postural hypotension is the most obvious result of cardiovascular neurogenic damage, but in recent years studies of autonomic function have revealed evidence of cardiac denervation which is predominantly vagal $[4,5]$ and occasionally the heart may be totally denervated [6]. The consequences of cardiac denervation are sometimes a rapid or even a fixed heart rate (HR); cardiorespiratory arrests, and sudden, unexplained deaths have also been observed in these patients.

Autonomic neuropathy is most conveniently detected by testing cardiovascular reflex responses to various stimuli [7], such as to forced expiration against resistance the Valsalva manoeuvre [8-11], and to sustained handgrip [12]. However measurement of the loss of normal heart rate variation, due to cardiac denervation, probably provides the best and simplest bedside test of autonomic function, and has been extensively used [13-16]. Loss of the normal heart rate responses which occur on standing can also provide evidence of autonomic damage $[13,17]$. By means of heart rate monitoring using either sophisticated heart rate meters with [18] or without computers, or a simple electrocardiograph [17] objective and quantitative assessment can be made of the degree of autonomic damage.

We describe here our experience with heart rate monitoring over the past five years with an assessment of its role in the diagnosis of autonomic neuropathy and in the study of its natural history.

\section{Patients}

We have tested 287 diabetics, (14 have been included twice making a total of 301 tests, see below) and a control group of 54 normal subjects (mean age $33.7 \pm 1.3$ years SEM). All but three 
of the diabetics were insulin-dependent, and all subjects were between 20 and 49 years old (Tables 1 and 2). Those over 50 years were excluded because HR responses decline with age [19]. Diabetics were allocated to one of 3 groups depending on the clinical severity of the neuropathy: nerve conduction studies were not performed.

1) Diabetics without clinical neuropathy (143 patients) had no clinical signs of peripheral neuropathy, and knee and ankle jerks were intact. Thirty two patients with ankle jerks present on reinforcement or with one ankle jerk only were included.

2) Diabetics with peripheral neuropathy (94 patients) were defined as having, as a minimum, absent ankle jerks. Autonomic symptoms were not present.

3) Diabetics with symptomatic autonomic neuropathy (64 patients) who had one or more symptoms or signs of autonomic neuropathy. These were (a) Postural hypotension (25 patients; 39\%), defined by the presence of postural symptoms together with a fall in systolic blood pressure of $30 \mathrm{~mm} \mathrm{Hg}$ or more on standing (23 patients) or a standing systolic blood pressure of $90 \mathrm{~mm} \mathrm{Hg}$ or less (2 patients). (b) Diarrhoea of characteristic pattern with nocturnal bouts and episodes of faecal incontinence (43 patients; 67\%).

Table 1. Distribution by age bands (20-29 years, 30-39 years, $40-49$ years) of subjects in each clinical group

\begin{tabular}{lllll}
\hline Clinical groups & \multicolumn{2}{l}{$\begin{array}{l}\text { Numbers in each } \\
\text { age group }\end{array}$} & $\begin{array}{l}\text { Total } \\
\text { number }\end{array}$ \\
\cline { 2 - 4 } & $\begin{array}{l}20-29 \\
\text { years }\end{array}$ & $\begin{array}{l}30-39 \\
\text { years }\end{array}$ & $\begin{array}{l}40-49 \\
\text { years }\end{array}$ & \\
\hline $\begin{array}{l}\text { 1. Diabetics without } \\
\text { neuropathy }\end{array}$ & 43 & 52 & 48 & 143 \\
$\begin{array}{l}\text { 2. Diabetics with } \\
\text { peripheral neuropathy }\end{array}$ & 16 & 32 & 46 & 94 \\
$\begin{array}{l}\text { 3. Diabetics with } \\
\text { autonomic neuropathy }\end{array}$ & 11 & 23 & 30 & 64 \\
4. Normal subjects & 21 & 16 & 17 & 54 \\
\hline
\end{tabular}

Group 4 v. group $1 \chi^{2}=1.51$ not significant

Group 4 v. group $2 \chi^{2}=9.222 \mathrm{P}<0.01$

Group 4 v. group $3 \chi^{2}=7.502 \mathrm{P}<0.025$ (c) Gustatory sweating (37 patients; 58\%), being facial sweating when eating tasty food [20]. (d) Oesophageal and/or gastric atony ( 9 patients; $14 \%$ ) shown by contrast radiology (usually done during the investigation of diarrhoea) and defined as absence of peristalsis. (e) Bladder atony ( 5 patients; $8 \%$ ) manifested by palpable, painless bladder distension. (f) Unexplained cardio-respiratory arrest associated with surgical anaesthesia (4 patients; 6\%) [21].

More than half of the diabetics with autonomic neuropathy had more than one of these autonomic features. Peripheral neuropathy (i. e. at least absent ankle jerks) was present in all but 4 of the 64 patients. Impotence was not included as a diagnostic feature because of difficulties in its assessment. The age distribution of subjects in each group is given in Table 1. Normal subjects and diabetics without neuropathy had a similar age distribution, whereas diabetics with peripheral and with autonomic neuropathy included a significantly greater proportion of older subjects.

All the patients tested were ambulant and their diabetes was reasonably controlled: none were in ketoacidosis or heart failure. Seven patients were on treatment for hypertension and five for angina ( 2 of them with hypertension as well), and 6 of these were on $\beta$-receptor blocking drugs (4 propranolol, 2 oxprenolol) which do not affect heart rate variation [4]. Four patients were on drugs with known anticholinergic activity: two on antidepressants, one on perhexiline for angina, and one patient taking Lomotil (diphenoxylate with atropine).

The presence of retinopathy, assessed by fundoscopy, and of nephropathy (persistent proteinuria) in the three groups of diabetics is shown in Table 2.

\section{Methods}

Subjects were connected by 3 chest leads to an oscilloscope and a Hewlett-Packard instantaneous heart rate (HR) monitor. They rested supine for a few minutes and once a stable HR record was obtained they stood up by the bedside for at least one minute. After lying down again HR variation was recorded during deep breathing at a regular rate of 6 deep breaths per minute $(5$ seconds in, 5 seconds out) for about two minutes.

HR variation on deep breathing was assessed by measuring the difference between maximum and minimum heart rates (in beats per minute) over 10 breaths and a mean of the 20 readings (10 up and 10 down) gave the "heart rate variation (HRV) score" (Fig. 1).

Table 2. Mean ages and durations of diabetes, presence of retinopathy and of nephropathy (persistent proteinuria) in the 3 groups of diabetics

\begin{tabular}{|c|c|c|c|c|c|c|c|}
\hline \multirow[t]{2}{*}{ Diabetic groups } & \multirow{2}{*}{$\begin{array}{l}\text { Total }^{\mathrm{a}} \\
\text { number }\end{array}$} & \multirow{2}{*}{$\begin{array}{l}\text { Mean age } \\
\pm \text { SEM } \\
\text { (years) }\end{array}$} & \multirow{2}{*}{$\begin{array}{l}\text { Mean duration } \\
\text { of diabetes } \\
\pm \text { SEM (years) }\end{array}$} & \multicolumn{3}{|c|}{ Retinopathy ${ }^{\mathrm{d}}$} & \multirow{2}{*}{$\begin{array}{l}\text { Persistent } \\
\text { proteinuria }\end{array}$} \\
\hline & & & & None & Background & Proliferative & \\
\hline $\begin{array}{l}\text { Without peripheral } \\
\text { neuropathy }\end{array}$ & 143 & $35.8 \pm 0.5$ & $18.5 \pm 0.9$ & $78(55 \%)$ & $46(32 \%)$ & $19(13 \%)$ & $8(6 \%)$ \\
\hline $\begin{array}{l}\text { With peripheral } \\
\text { neuropathy }\end{array}$ & 94 & $38.3 \pm 0.7$ & $22.2 \pm 1.0$ & $23(24 \%)$ & $42(45 \%)$ & $29(31 \%)$ & $29(20 \%)$ \\
\hline $\begin{array}{l}\text { With autonomic } \\
\text { symptoms }\end{array}$ & 64 & $37.5 \pm 0.7$ & $21.0 \pm 1.1$ & $3(5 \%)$ & $22(34 \%)$ & $39(61 \%)$ & $28(44 \%)$ \\
\hline
\end{tabular}

a 14 diabetics without neuropathy are included also in the groups of diabetics with neuropathy (13 patients) and with autonomic symptoms ( 1 patient) because on subsequent testing they had developed clinical evidence of neuropathy (see text)

${ }^{b}$ Using t-test: group 1 v. $2,2 \mathrm{P}<0.05$; group 1 v. 3 and 2 v. 3 , not significant

${ }^{c}$ Using t-test: group 1 v. $2,2 \mathrm{P}<0.01$; group 1 v. 3 and 2 v. 3 , not significant

${ }^{\mathrm{d}}$ Using chi-square test: group 1 v. $2, \chi^{2}=23.07,2 \mathrm{P}<0.001$; group 2 v. $3, \chi^{2}=18.06,2 \mathrm{P}<0.001$ 
Normal response

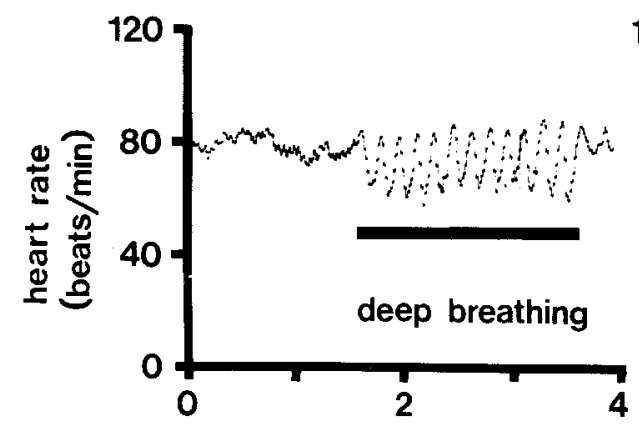

Normal response

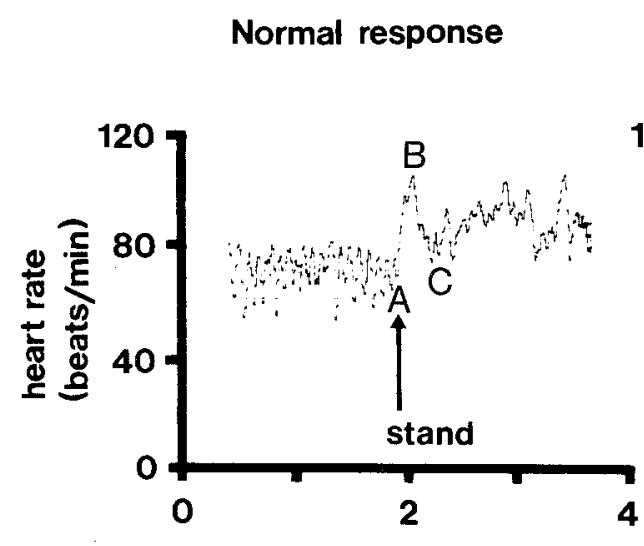

Diabetic autonomic neuropathy

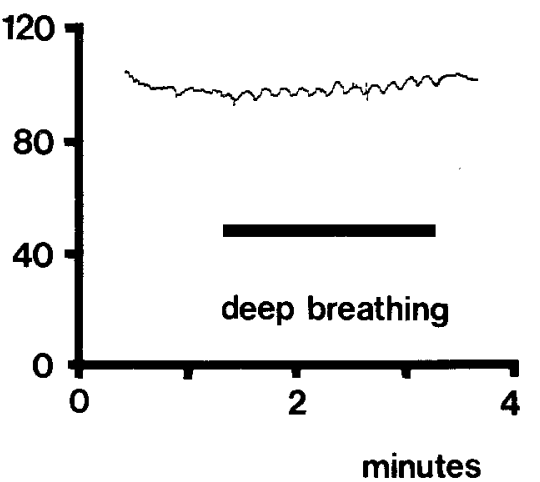

Diabetic autonomic neuropathy

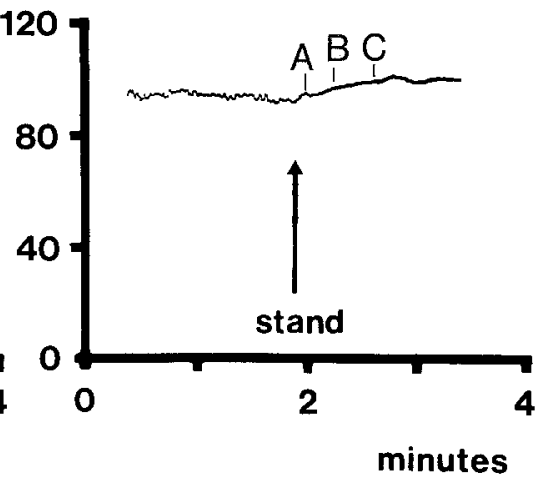

Fig. 1. HR variation on deep breathing, at 6 breaths/minute, in a normal subject (left), and in a diabetic with autonomic neuropathy (right). The HR monitor detects each $R$ wave from the ECG, and each R.R. interval is converted into its equivalent heart-rate in beats/minute
The HR response to standing was assessed by two measurements (Fig. 2). First, the "HR increase on standing" was measured, which is the difference between the HR at peak (B) and the resting $\mathrm{HR}(\mathrm{A}),(\mathrm{B}-\mathrm{A})$. In those patients with autonomic neuropathy who had a more gradual increase in HR with loss of the peak and overshoot the HR increase 15 seconds after standing was measured instead. Second, the "standing HR ratio" was measured, which is the peak HR (B) divided by HR at the end of the overshoot (C). In diabetics with autonomic neuropathy who lost the overshoot the HR ratio was expressed as the HR 15 seconds after standing (B) divided by the HR 30 seconds after standing (C).

When diabetics had been tested more than once, one record only was selected randomly and included in the analysis, unless neuropathy had progressed; 14 diabetics initially without neuropathy had subsequent tests when there was evidence of peripheral neuropathy (13 patients) or of autonomic neuropathy (1 patient) and these subsequent tests were included in the relevant groups thus making a total of 301 records in the analysis. Serial HRV tests were performed in 21 diabetics over 3 to 5 years and the results of these are presented.

For statistical analysis Student's t test, the Mann Whitney U test and the chi-square test were used as indicated, employing a 5 per cent level of significance.

\section{Results}

\section{Normal Values}

Results from all subjects between 20 and 49 years old have been analysed together (Table 3, Fig. 3), despite the small but consistent decrease in mean scores of HRV and HR increase on standing which occur with increasing age (Fig. 4). All 3 measurements showed a wide normal range. Abnormal scores have been defined as those more than 2 standard deviations below the mean value in normal subjects. Scores between 1.5 and 2 SD below the mean have been called borderline. The abnormal score for the HRV was less than 9, and borderline between 9 and 12. Abnormal values for $H R$ increase on standing were less than 12, and borderline between 12 and 15 . Abnormal values for the HR ratio were less than 1.04 and borderline between 1.04 and 1.11 (Table 3 ). 
Table 3. Grouped data for the 3 heart rate tests in normal subjects and the 3 groups of diabetics

\begin{tabular}{|c|c|c|c|c|}
\hline $\begin{array}{l}\text { Test } \\
\text { no. }\end{array}$ & Mean $\pm S^{a}$ & Range & $\begin{array}{l}\% \text { abnormal } \\
\text { in diabetics }\end{array}$ & $\begin{array}{l}\% \text { abnormal }+ \\
\text { borderline in } \\
\text { diabetics }^{c}\end{array}$ \\
\hline
\end{tabular}

\begin{tabular}{|c|c|c|c|c|}
\hline $\begin{array}{l}\text { Normal subjects } \\
\text { 1. HRV (54) } \\
\text { 2. HR increase (53) } \\
\text { 3. HR ratio (52) }\end{array}$ & $\begin{array}{l}24.6 \pm 7.8 \\
27.1 \pm 7.8 \\
1.37 \pm 0.16\end{array}$ & $\begin{array}{c}9-43 \\
12-48 \\
1.08-1.73\end{array}$ & & \\
\hline $\begin{array}{l}\text { Diabetics without } \\
\text { peripheral neuropathy } \\
\text { 4. HRV (143) } \\
\text { 5. HR increase (140) } \\
6 . \text { HR ratio (139) }\end{array}$ & $\begin{array}{l}22.1 \pm 9.3 \\
26.0 \pm 7.8 \\
1.24 \pm 0.16\end{array}$ & $\begin{array}{c}2-44 \\
10-48 \\
1.01-1.69\end{array}$ & $\begin{array}{l}7 \% \\
3 \% \\
4 \%\end{array}$ & $\begin{array}{l}17 \% \\
10 \% \\
27 \%\end{array}$ \\
\hline $\begin{array}{l}\text { Diabetics with } \\
\text { peripheral neuropathy } \\
\text { 7. HRV (94) } \\
\text { 8. HR increase (88) } \\
\text { 9. HR ratio }(88)\end{array}$ & $\begin{array}{l}13.7 \pm 7.4 \\
19.9 \pm 7.6 \\
1.16 \pm 0.14\end{array}$ & $\begin{array}{c}1-36 \\
3-41 \\
0.95-1.64\end{array}$ & $\begin{array}{l}30 \% \\
13 \% \\
10 \%\end{array}$ & $\begin{array}{l}55 \% \\
27 \% \\
47 \%\end{array}$ \\
\hline $\begin{array}{l}\text { Diabetics with } \\
\text { autonomic symptoms } \\
\text { 10. HRV (64) } \\
\text { 11. HR increase }(58) \\
\text { 12. HR ratio (58) }\end{array}$ & $\begin{array}{c}4.8 \pm 3.8 \\
10.5 \pm 7.7 \\
1.03 \pm 0.07\end{array}$ & $\begin{array}{c}1-17 \\
0-27 \\
0.85-1.29\end{array}$ & $\begin{array}{l}84 \% \\
57 \% \\
57 \%\end{array}$ & $\begin{array}{l}97 \% \\
76 \% \\
90 \%\end{array}$ \\
\hline
\end{tabular}

\section{Results in Diabetics}

Autonomic function assessed by all 3 tests was similar in diabetics without neuropathy and normal subjects, but there was a progressive decline in diabetics with peripheral neuropathy and those with autonomic symptoms as well (Table 3, Fig. 3).

Sixty two of the 64 patients with autonomic symptoms had HRV scores of 12 or less, with $84 \%$ of tests $(54 / 64)$ clearly abnormal and 8 of the remaining 10 borderline. HR changes on standing (HR increase and HR ratio) were abnormal in only $57 \%$ of patients $(33 / 58)$ in both tests.

Some diabetics without autonomic symptoms had abnormal tests. Thirty per cent (27/94) of diabetics with peripheral neuropathy had abnormal HRV scores. Of those diabetics without peripheral neuropathy $7 \%$ had scores outside the range recorded in the 54 normals. Standing responses were again less frequently abnormal in these diabetics. The HR increase on standing was abnormal in 13\% (11/ 88) of diabetics with peripheral neuropathy, and the standing HR ratio was abnormal in 10\% (9/88).

\section{Reproducibility of the Tests}

Reproducibility of the HRV test and the HR increase on standing were assessed by measuring the differ- ence between two tests done on the same subjects less than 12 months apart. Differences between the scores were greater in the higher range, whereas those with low or abnormal scores showed less variability on repeated testing (Table 4).

Among diabetics with serial tests there were 59 patients who had an abnormal HRV score and in whom the test was repeated: $97 \%$ remained abnormal or borderline. Similarly, among 30 diabetics who had abnormal HR changes on standing (HR increase or ratio) a repeat test was still abnormal or borderline in $90 \%$.

\section{Consistency of Heart Rate Variation during Deep Breathing}

Increasing neuropathy caused not only a decline in the overall HRV score but also a greater variability of HRV from breath to breath. Thus the mean coefficient of variation was $30 \%$ for deep breathing scores less than 10 , and $23 \%, 17 \%, 13 \%$ and $10 \%$ for scores of $10-19,20-29,30-39$ and 40 and over respectively. Sometimes this variation was due to a progressive decrease in HRV as the test proceeded, despite adequate deep breathing. About one fifth of diabetics with neuropathy had a relatively large change in HR with the first breath followed by much smaller variations in HR subsequently. 

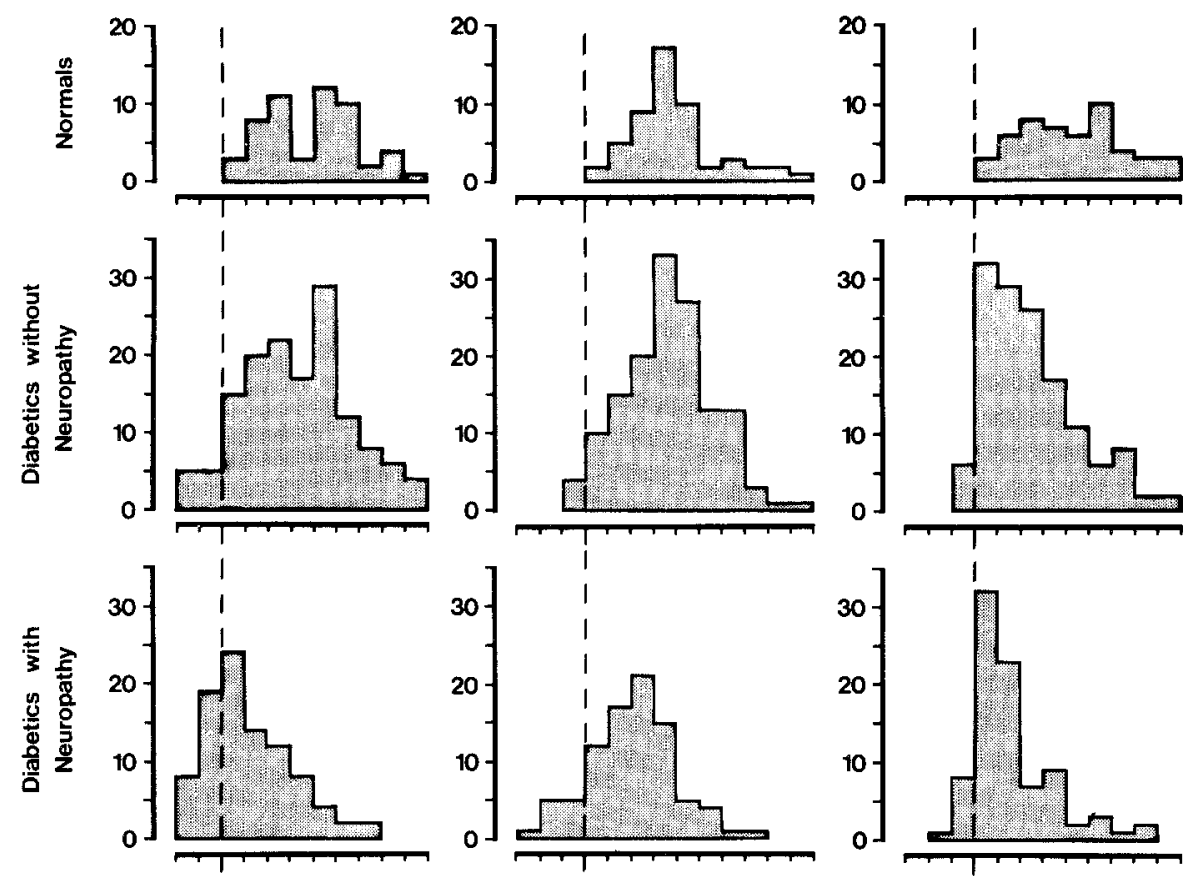

Fig. 3. Responses of HR variation on deep breathing, HR increase on standing and standing HR ratios in normal subjects (54), diabetics without neuropathy (143), diabetics with peripheral neuropathy but no autonomic symptoms (94), and those with autonomic symptoms (64). The lower limits of normal (mean $2 \mathrm{SD}$ ) are indicated by the vertical interrupted lines. Using the MannWhitney $U$ test, in diabetics without neuropathy the results of HRV on deep breathing and the HR increase on standing were not significantly different from normal. The standing HR ratio in diabetics without neuropathy and all 3 tests in diabetics with peripheral neuropathy and with autonomic neuropathy were different $(2 \mathrm{P}<0.001)$ from normal

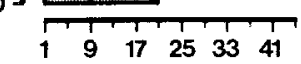

Heart-rate Variation on Deep Breathing

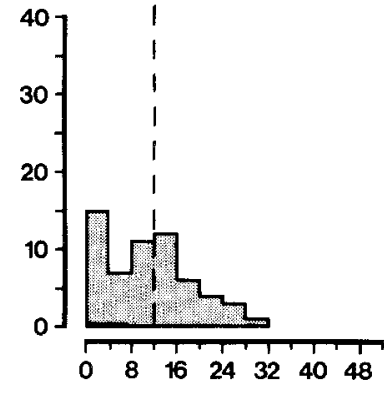

Heart-rate Increase

on Standing

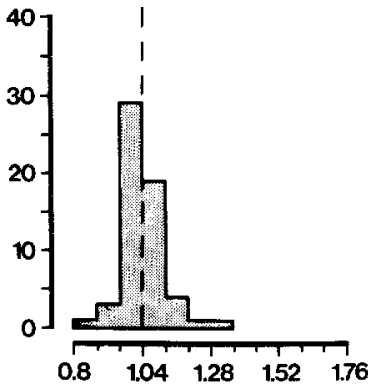

Standing Heart - rate Ratio 


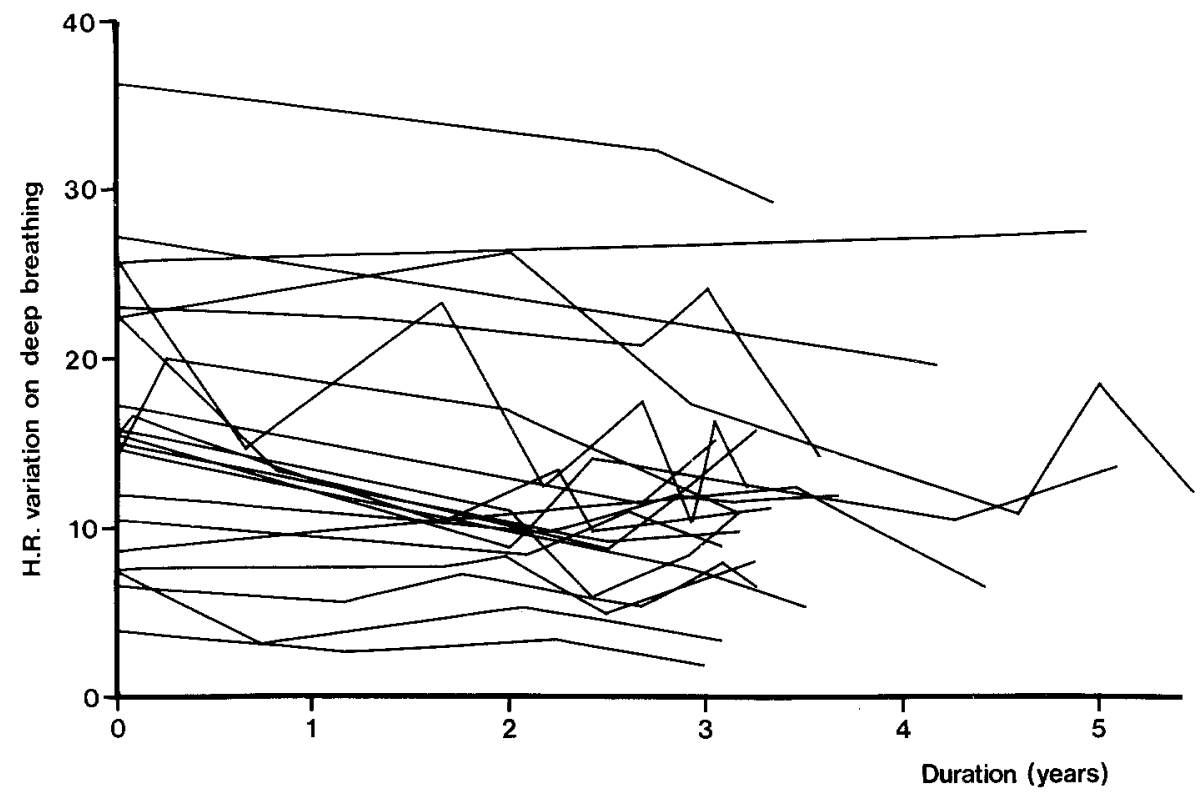

Fig. 5. Serial scores of HR variation on deep breathing in 21 diabetics over 3 to 5 years duration of testing

\section{Long-term Changes in Heart Rate Variation}

Twenty one diabetics had repeated tests for between 3 and 5 years (Fig. 5). Overall there was little change in the HRV during this time although a small average decrease of about 1.0 each year was calculated, being greater in those diabetics with normal scores and less in those already abnormal.

There were 10 diabetics without autonomic symptoms but with repeatedly abnormal HRV scores for between 1 and 3 years. Only one of these 10 diabetics developed a definite autonomic symptom (diabetic diarrhoea) during the period of observation.

\section{Discussion}

Instantaneous heart rate monitoring provides a simple means of detecting autonomic neuropathy in diabetics by measurement of HR responses to deep breathing and to standing. They provide a quantitative assessment of the degree of autonomic damage. Those diabetics with well substantiated autonomic symptoms ( 62 out of 64 patients) had impaired HRV during deep breathing, and $84 \%$ of them had grossly abnormal scores below 9. This test is more sensitive than that recording HR changes on standing and probably the best simple test of autonomic function.

Measurement of $\mathrm{HR}$ variation can be made at rest either lying [15] or standing [16]. In a resting subject breathing quietly there is some HR variation from heart-beat to heart-beat; but regular deep breathing greatly exaggerates this effect as the heart
Table 4. Reproducibility of the tests of $H R$ variation on deep breathing and of HR increase on standing. The second tests were done less than 12 months after the first tests; and the difference between the scores has been expressed as the mean \pm SD. All subjects tested were diabetics, and the number tested is given in brackets

\begin{tabular}{|c|c|c|c|}
\hline \multicolumn{2}{|c|}{$H R$ variation on deep breathing } & \multicolumn{2}{|c|}{$H R$ increase on standing } \\
\hline Initial test & $\begin{array}{l}\text { Second test - } \\
\text { mean } \\
\text { difference } \\
\text { from 1st test }\end{array}$ & Initial test & $\begin{array}{l}\text { Second test - } \\
\text { mean } \\
\text { difference } \\
\text { from 1st test }\end{array}$ \\
\hline less than 10 & $2.6 \pm 2.2(52)$ & less than 10 & $3.6 \pm 2.9(18)$ \\
\hline $10-19$ & $4.7 \pm 3.4(40)$ & $10-19$ & $3.4 \pm 3.6(60)$ \\
\hline 20 and over & $5.6 \pm 4.0(27)$ & $20-29$ & $4.7 \pm 4.5(50)$ \\
\hline & & 30 and over & $7.7 \pm 6.3(19)$ \\
\hline
\end{tabular}

adjusts to the increase in venous return [22]. HRV on deep breathing, the technique used in these studies, discriminates between those with and without vagal neuropathy of the heart better than measurements made during quiet breathing [14]. The normal HR variation on deep breathing is abolished by parasympathetic blockade with atropine but unaffected by sympathetic blockade with propranolol [4]. Thus loss of HR variation is most probably due to vagal neuropathy $[4,5]$. Heart rate variation can also be impaired in coma [23], heart failure [24], and theoretically by such drugs as phenothiazines and tricyclic antidepressants which have some anticholinergic activity.

Heart rate normally increases rapidly on standing and then overshoots (Fig. 2) but in diabetics with autonomic neuropathy there is a more gradual 
increase in heart rate often with loss of the overshoot and in a few there is no change in the HR at all suggesting complete cardiac denervation. These responses depend on intact sympathetic and parasympathetic innervation [25]. Similar HR changes with an overshoot tachycardia are seen at the start of light exercise [26]. The immediate, rapid increase in HR in both situations is due to vagal withdrawal and the overshoot in HR to a transient increase in vagal tone. Parasympathetic blockade with atropine modifies these responses and then HR increase on standing occurs gradually as in diabetics with autonomic neuropathy [17]. In contrast to the HRV test, the standing responses were clearly abnormal in only $57 \%$ of diabetics with autonomic symptoms, probably because sympathetic innervation may remain intact even in the presence of severe vagal damage [5, 27]. Thus diabetics with sufficient sympathetic nerve damage to cause postural hypotension more frequently $(76 \%)$ had abnormal standing HR responses.

While abnormal tests were the rule in patients with autonomic symptoms, they were also found in those with neuropathy without autonomic symptoms; one third of them had abnormal HRV scores. One woman aged 44 years with diabetes for 20 years, showed severe abnormalities of autonomic function (HRV of 3) yet there was neither clinical nor electrophysiological evidence of peripheral neuropathy and only minimal background retinopathy. These observations point to the existence of asymptomatic autonomic neuropathy which on rare occasions may be the earliest manifestation of neuropathy [16].

Heart rate variation tests were performed repeatedly on 21 diabetics over a period of 3 to 5 years. There was little overall change during this time although a small mean decline in HRV of about 1.0 per year was calculated. There was also a small decrease of HRV with increasing age (Fig. 4). Serial HRV tests in ten diabetics remained abnormal over 1 to 3 years, yet autonomic symptoms developed in only 1 diabetic during this time. Thus, abnormal tests usually indicate permanent autonomic dysfunction which may exist for some years before the onset of autonomic symptoms. However, decline of HRV is not inevitable, and tests may remain normal in some patients after 30 to 40 years of diabetes even in the presence of proliferative retinopathy.

Once autonomic function tests become abnormal they usually remain so. The only other study which examined sequential tests of autonomic function [28] showed improvement in only 1 of 10 patients with abnormal tests. No effect of diabetic control on tests of autonomic function has been found, even after treatment of ketoacidosis [29], although in this study observations were not made until the second day after admission. The tests probably show too much variation to detect the subtle changes which might take place with improvement of diabetic control.

Cardiorespiratory arrests have been described in diabetics with cardiac denervation, usually during or after surgery [21]. All patients with HRV abnormalities undergoing even minor operative procedures are now monitored with special care; indeed the HRV of patients with severe neuropathy should always be assessed pre-operatively in order to detect those at risk. Whether impaired autonomic reflexes are responsible for some sudden unexplained deaths in diabetics is still uncertain $[21,28]$.

An important advantage of heart rate monitoring is that it is a simple bedside test and can be adapted for use with an ordinary electrocardiograph thus avoiding the need for any special equipment. Ewing et al. [17] described a method of assessment of heart rate ratios by comparing the 15 th with the 30 th $\mathrm{R}-\mathrm{R}$ interval after standing up, and they have shown the relationship of this test to the presence of autonomic symptoms. Its simplicity commends this test, although from our own studies we believe that measurement of HRV during deep breathing provides the most sensitive index of autonomic dysfunction. It should be quite simple to adapt this test for use with an electrocardiograph [30].

Acknowledgements. JDM has been supported by the King's College Hospital Voluntary Research Trust and by Sterling Winthrop Ltd., M. McB. P. by the British Heart Foundation and J. C. by the British Diabetic Association. We are grateful to Dr. D. A. Pyke for his guidance and help, Mrs. A. Spink for typing the manuscript, and Miss Linda Hunt for statistical help.

\section{References}

1. Rundles RW (1945) Diabetic neuropathy: general review with report of 125 cases. Medicine (Baltimore) 24: 111-160

2. Keen H (1959) Autonomic neuropathy in diabetes mellitus. Postgrad Med J 35: 272-280

3. Hosking DJ, Bennett T, Hampton JR (1978) Diabetic autonomic neuropathy. Diabetes 27: 1043-1054

4. Wheeler T, Watkins PJ (1973) Cardiac denervation in diabetes. Br Med J IV: 584-586

5. Lloyd-Mostyn RH, Watkins PJ (1975) Defective innervation of the heart in diabetic autonomic neuropathy. Br Med J III: $15-17$

6. Lloyd-Mostyn RH, Watkins PJ (1976) Total cardiac denervation in diabetic autonomic neuropathy. Diabetes 25: 748-751

7. Ewing DJ (1978) Cardiovascular reflexes and autonomic neuropathy. Clin Sci Mol Med 55: 321-327

8. Sharpey-Schafer EP, Taylor PJ (1960) Absent circulatory reflexes in diabetic neuritis. Lancet I: 559-562

9. Levin AB (1966) A simple test of cardiac function based upon the heart rate changes induced by the Valsalva manoeuvre. Am J Cardiol 18: 90-99

10. Ewing DJ, Campbell IW, Burt AA, Clarke BF (1973) Vascular reflexes in diabetic autonomic neuropathy. Lancet II: $1354-1356$ 
11. Bennett T, Hosking DJ, Hampton JR (1976) Baroreflex sensitivity and responses to the Valsalva manoeuvre in subjects with diabetes mellitus. J Neurol Neurosurg Psychiatry 39: 178-183

12. Ewing DJ, Irving JB, Kerr F, Wildsmith JAW, Clarke BF (1974) Cardiovascular responses to sustained handgrip in normal subjects and in patients with diabetes mellitus. Clin Sci Mol Med 46: 295-306

13. Page M McB, Watkins PJ (1977) The heart in diabetes: autonomic neuropathy and cardiomyopathy. Clin Endocrinol Metab 6: 377-388

14. Bennett T, Fentem PH, Fitton D, Hampton JR, Hosking DJ, Riggott PA (1977) Assessment of vagal control of the heart in diabetes. Measure of RR interval variation under different conditions. Br Heart J 39: 25-28

15. Gundersen HJG, Neubauer B (1977) A long term diabetic autonomic nervous abnormality. Reduced variation in resting heart rate measured by a simple and sensitive method. Diabetologia 13: 137-140

16. Murray A, Ewing DJ, Campbell IW, Neilson JMM, Clarke BF (1975) RR interval variations in young male diabetics. $\mathrm{Br}$ Heart J 37: 882-885

17. Ewing DJ, Campbell IW, Murray A, Neilson JMM, Clarke BF (1978) Immediate heart rate response to standing: simple test for autonomic neuropathy in diabetes. Br Med J I: 145-147

18. Cashman PMM (1977) The use of R-R interval and different histograms in classifying disorders of sinus rhythm. J Med Eng Technol 1: 20-28

19. Hellman JB, Stacey RW (1976) Variation of sinus arrhythmia with age. J Appl Physiol 41: 734-738

20. Watkins PJ (1973) Facial sweating after food: a new sign of diabetic autonomic neuropathy. Br Med J I: 583-587

21. Page M McB, Watkins PJ (1978) Cardiorespiratory arrest and diabetic autonomic neuropathy. Lancet I: $14-16$
22. Melcher A (1976) Respiratory sinus arrhythmia in man: a study in heart rate regulating mechanisms. Acta Physiol Scand [Suppl] 435

23. Vallabona C, Cardus D, Spencer WA, Hoff HE (1965) Patterns of sinus arrhythmia in patients with lesions of the central nervous system. Am J Cardiol 16: 379-389

24. Eckberg DL, Drabinsky M, Braunwald E (1971) Defective cardiac parasympathetic control in patients with heart disease. N Engl J Med 285: 877-883

25. Robinson BF, Epstein SE, Beiser GD, Braunwald E (1966) Control of heart rate by the autonomic nervous system. Circ Res 19: 400-411

26. Fagreus L, Linnarsson D (1976) Autonomic origin of heart rate fluctuations at the onset of muscular exercise. J Appl Physiol 40: 679-682

27. Bennett T, Hosking DJ, Hampton JR (1975) Cardiovascular control in diabetes mellitus. Br Med J II: 585-587

28. Ewing DJ, Campbell IW, Clarke BF (1976) Mortality in diabetic autonomic neuropathy. Lancet I: 601-603

29. Campbell IW, Ewing DJ, Harrower ABD, Neilson JMM, Fraser DM, Baldwa VS, Murray A, Clarke BF (1976) Peripheral and autonomic nerve function in diabetic ketoacidosis. Lancet I: 167-169

30. Sundkvist G, Almér L-O, Lilja B (1979) Respiratory influence on heart rate in diabetes mellitus. Br Med J I: 924-925

Received: March 1, 1979,

and in revised form: January 25,1980

Dr. P. J. Watkins

Diabetic Department

King's College Hospital

London SE5 9RS

England 